\title{
As relações entre discursos representados em textos de Materiais Curriculares Educativos sobre Matemática ${ }^{1}$
}

Reinaldo Feio Lima²

Andréia Maria Pereira de Oliveira ${ }^{3}$

\section{Resumo}

Neste artigo, nosso objetivo foi identificar e compreender as relações entre discursos representados em textos de Materiais Curriculares Educativos (MCE) sobre Matemática sob as lentes da teoria de Basil Bernstein. A natureza da pesquisa é qualitativa e os dados foram produzidos por meio da análise de documentos, à luz de construtos da teoria dos códigos de Basil Bernstein, o qual propõe uma linguagem de descrição interna e externa. Os resultados apontam que tais materiais sugerem que há um silenciamento do discurso interdisciplinar representado nos textos dos MCE e um distanciamento do discurso acadêmico do não acadêmico, que foi negado nos textos dos Materiais Curriculares Educativos sobre Matemática.

Palavras-chave: Relações Discursivas; Textos; Materiais Curriculares Educativos sobre Matemática.

\section{The relation between discourses presented in texts of Educational Curriculum Materials on Mathematics}

\begin{abstract}
In this article, our goal was to identify and understand the relations between discourses presented in texts of Educational Curriculum Materials (ECM) according to the lens of the Basil Bernstein theory. The nature of the research is qualitative and the data were produced through the analysis of documents, in the light of constructs of the theory of codes of Basil Bernstein, which proposes a language of internal and external description. The results indicate that these materials suggest, through theirs texts, that there is a silence of the interdisciplinary discourse presented in the MCE texts. We had also identified that there is a distancing from academic discourse from nonacademic one, which were denied in the texts of the Educational Curriculum Materials on Mathematics. Keywords: Discursive Relations; Texts; Educational Curriculum Materials on Mathematics.
\end{abstract}

\section{Considerações iniciais}

Este artigo é fruto de uma pesquisa sobre a mensagem da prática pedagógica, representada em textos de Materiais Curriculares Educativos (MCE) sobre Matemática, apresentado no XXIII Encontro Brasileiro de Estudantes de Pós-Graduação em Educação Matemática (EBRAPEM), realizado nos dias 25, 26 e 27 de outubro de 2019, na Universidade

\footnotetext{
${ }^{1}$ Uma versão preliminar deste artigo foi apresentada no XXIII Encontro Brasileiro de Estudantes de Pós-Graduação em Educação Matemática, realizado nos dias 25, 26 e 27 de outubro de 2019, na UNICSUL/SP.Para esta versão, o artigo teve trechos atualizados e ampliados.

${ }^{2}$ Universidade Federal do Sul e Sudeste do Pará, Santana do Araguaia/PA. reinaldo.lima@unifesspa.edu.br

${ }^{3}$ Universidade Federal da Bahia, Salvador/BA. ampo@ufba.br
} 
Cruzeiro do Sul (UNICSUL), São Paulo, Brasil. Na ocasião, foram solicitadas pelos membros do Grupo de Discussão (GD) a ampliação da discussão e, posteriormente, a submissão em periódicos da área da Educação ou Educação Matemática.

Com vista a ampliar a investigação, debruçamos na relação entre os discursos acadêmicos, não acadêmicos, intradisciplinar e interdisciplinar. Temos a Teoria de Basil Bernstein como principal aporte teórico e metodológico, fornecendo uma maneira de olhar e compreender as relações discursivas veiculadas nos textos dos Materiais Curriculares Educativos sobre Matemática. Neste artigo, buscamos responder à seguinte questão: Como as relações entre os discursos (intradisciplinares, interdisciplinares, acadêmicos e os não acadêmicos) são representadas nos textos dos MCE? No sentido de encontrar resposta a esta questão, o estudo teve como principal objetivo identificar e compreender as relações entre discursos representados em textos de Materiais Curriculares Educativos sobre Matemática.

Desta forma, estruturamos o artigo em cinco seções. Na primeira seção, circunstanciamos o objeto da pesquisa e as principais ideias que embasaram nosso estudo. Na segunda seção, apresentamos os principais conceitos da teoria de Basil Bernstein, o aporte teórico e metodológico, que forneceram constructos teóricos para identificar e compreender as relações entre discursos representados em textos de Materiais Curriculares Educativo sobre Matemática. Na terceira seção, explicitamos os aspectos metodológicos percorridos para alcançar o objetivo. Na quinta e última seção, apresentamos e analisamos os dados produzidos sobre as relações discursivas, à luz dos referenciais citados anteriormente, e discutimos seus resultados. Por último, temos as considerações finais.

\section{As relações entre discusos sob a ótica de Basil Bernstein}

A expressão Materiais Curriculares Educativos sobre Matemática refere-se aos materiais em Educação Matemática delineados para apoiar a aprendizagem de professores(as). Schneider e Krajcik (2002) argumentam que os MCE podem apresentar indícios de como pode ocorrer o apoio aos(às) professores(as) por meio dos elementos constituintes dos materiais, como planejamentos, sequenciamento de ações, narrativas de professores, soluções de estudantes, vídeos de aula etc. (DAVIS et al., 2010; DUKE; BECK, 1999). Compartilhando dessa assertiva, 
Remillard e Kim (2017) denominam esses elementos de educativos para professores(as), pois, além de representar possibilidades da organização da aula, constituem-se em fonte de novas aprendizagens (BARBOSA; OLIVEIRA, 2018).

Portanto, são materiais produzidos para serem utilizados na/para prática pedagógica, a qual, segundo Bernstein $(1990,1996,2000)$, constitui as relações que ocorrem em outros contextos, entre pais e filhos, médicos e pacientes, advogados e clientes, pastores/padres e fiéis. Nesta pesquisa, o termo "prática pedagógica" referiu-se às relações entre professor(a) e os estudantes e entre os estudantes, por meio das quais ocorreu a produção de textos.

Entendemos textos como qualquer forma de comunicação que pode ser escrita, falada, visual e/ou espacial, produzida por uma pessoa (BERNSTEIN, 2000). Neste artigo, admitimos como textos os elementos constituintes dos Materiais Curriculares Educativos sobre Matemática, os quais foram observados a partir da prática pedagógica.

Para Bernstein $(1990,1996,2000)$, as relações discursivas entre os discursos intradisciplinares, interdisciplinares, acadêmicos e os não acadêmicos, oriundas da prática pedagógica, são reguladas pelo poder (classificação) e controle (enquadramento) na relação de comunicação entre professor(a) e estudantes, podendo assumir valores fracos ou fortes (MORAIS; NEVES; FERREIRA, 2019; OLIVEIRA, 2010). A classificação refere-se ao conteúdo da comunicação. O enquadramento, por sua vez, refere-se ao modo como o conteúdo da comunicação é ensinado. Por exemplo, no que se refere ao conteúdo da comunicação, ele afirma que quanto maior for o grau de isolamento entre os conteúdos, mais forte será a classificação, mas se o isolamento for enfraquecido, tem-se uma classificação fraca.

Assim, relações intradisciplinares se referem à integração dos diferentes conteúdos abordados em uma mesma tarefa matemática, isto é, o relacionamento entre os vários conteúdos/assuntos abordados na mesma disciplina. Relações interdisciplinares se referem às relações entre diferentes disciplinas escolares, são relações que o(a) professor(a) estabelece ao incluir conteúdos de outras disciplinas, ao explicar os conteúdos durante a aula, por exemplo, a relação entre determinados conteúdos de Matemática com Física ou Química (MORAIS; NEVES; FERREIRA, 2019; COIMBRA, 2010).

Quanto à relação entre discursos acadêmico e não acadêmico, são as relações em que o(a) professor(a) toma "como ponto de partida o que o(a) estudante sabe acerca dos fenômenos 
estudados e, a partir daí, avança para conhecimentos e competências mais complexos" (GALIAN, 2011, p.771), ou também quando ele retoma, em meio às explicações de um novo conteúdo, exemplos do dia a dia dos(as) estudantes, isto é, faz conexões com a realidade na qual está inserido, a fim de facilitar a compreensão e a aprendizagem dos conceitos matemáticos (GALIAN, 2011). No presente artigo, a intradisciplinaridade, interdisciplinaridade e a relação entre o discurso acadêmico e não acadêmico foram analisadas em termos do conceito de classificação.

\section{Método}

Considerando o propósito deste artigo - investigar Materiais Curriculares Educativos sobre Matemática -, optou-se pela análise documental em uma pesquisa com método qualitativo dentro do paradigma interpretativo (GIL, 2010; ROCKWELL, 2009). Por esta razão, a ênfase desta pesquisa recaiu sobre a compreensão e interpretação dos dados produzidos sobre a ênfase nas relações intradisciplinares e interdisciplinares e das relações entre os conteúdos acadêmicos e não acadêmicos representados em textos de Materiais Curriculares Educativos sobre Matemática, usando textos como material empírico, ao invés de números (FLICK, 2009; RICHARDSON, 1999).

Quanto aos procedimentos de produção de dados qualitativos, esta investigação se valeu dos documentos que contituíram objeto de análise em que foram selecionados a partir da definição do foco do artigo. Foram ao todo três Materiais Curriculares Educativos sobre Matemática, todos de acesso público, publicados por grupos vinculados a Universidade Federal da Bahia, Universidade Estadual de Londrina e Universidade Federal Rural do Rio de Janeiro. A justificativa para seleção desses grupos é a de que, primeiramente, observou-se que produzem MCE e, por fim, voltados para área de conhecimento da Educação Matemática.

Para tal, apresenta-se a seguinte relação de documentos analisados na investigação:

Material Curricular Educativo $(\mathrm{MCE} 1)^{4}$ - "Recurso Multimídia na Formação de Professores" produzido pelo Grupo de Estudos e Pesquisas sobre Formação de Professores que Ensinam Matemática (Gepefopem) - está cadastrado no Diretório do Conselho Nacional de

${ }^{4}$ http://www.uel.br/grupo-estudo/gepefopem/apresentacao

Periódico Horizontes - USF - Itatiba, SP - Brasil - e020033 
Apoio Científico e Tecnológico (CNPq) pela Universidade Estadual de Londrina (UEL). Esse grupo possui como proposta estudar e investigar os fundamentos e os processos de constituição dos conhecimentos/saberes docentes na formação inicial (curso de Licenciatura em Matemática e Pedagogia), bem como na formação em serviço de professores que ensinam Matemática. Possui como coordenadora a Professora Dra. Márcia Cristina de Costa Trindade Cyrino.

Figura 1 - Ambiente virtual do caso multimídia "Os colares"

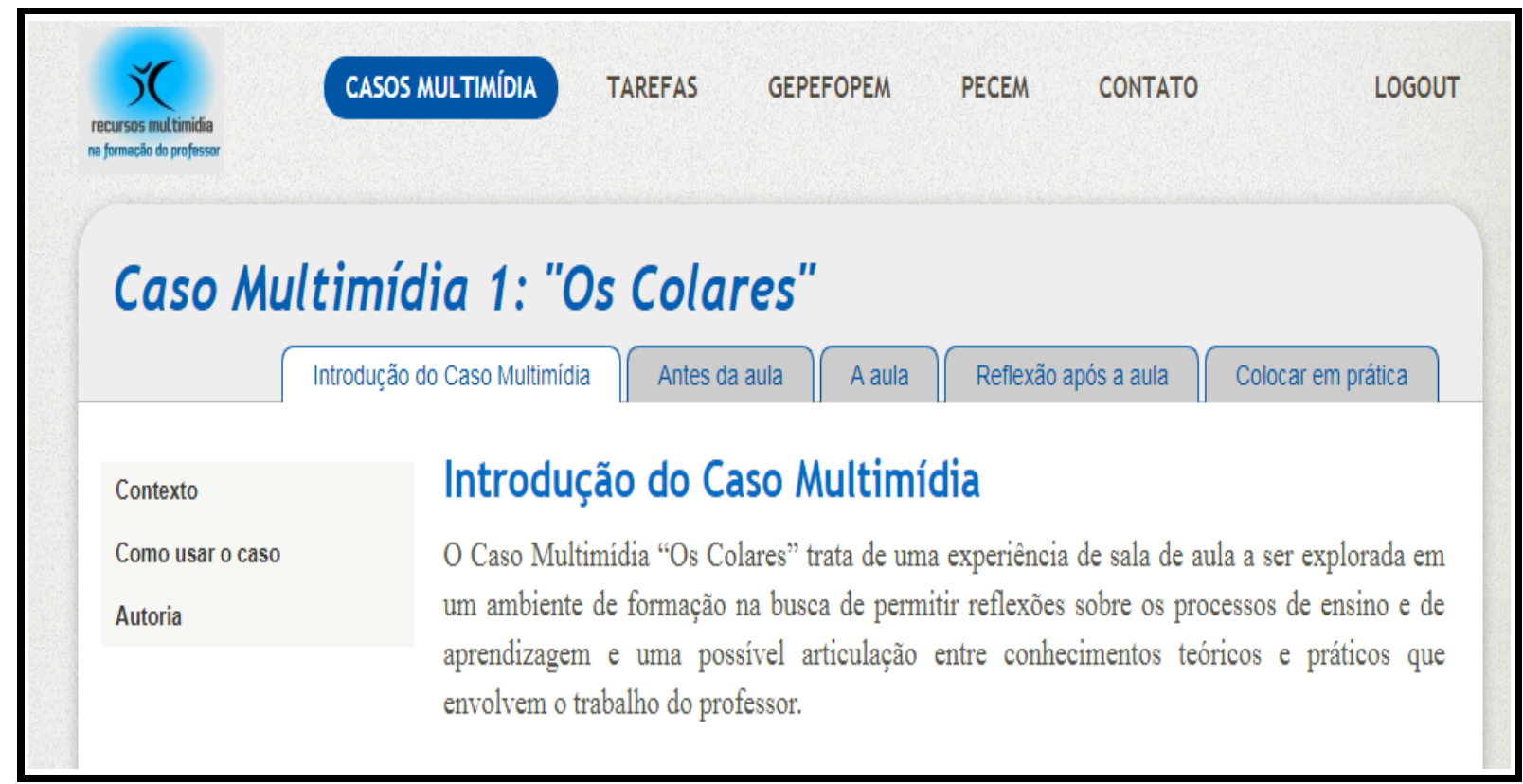

Fonte: www.rmpf.uel.br

Esse material explora o tópico matemático Álgebra do Ensino Fundamental, sendo composto de quatro seções para a apresentação de diferentes aspectos da aula, nomeadamente: 1) Antes da aula, 2) A Aula, 3) Reflexão após a aula e 4) Colocar em prática.

Material Curricular Educativo Online $(\mathrm{MCE} 2)^{5}$ - produzido pelo Grupo de Estudos e Pesquisas das Tecnologias da Informação e Comunicação em Educação Matemática (Gepeticem) contribui com o desenvolvimento de pesquisas no Programa de Pós-Graduação em Educação, Contextos Contemporâneos e Demandas Populares (PPGEduc) e no Programa de Pós-Graduação em Educação em Ciências e Matemática (PPGEduCIMAT), ambos da Universidade Federal Rural do Rio de Janeiro (UFRRJ). Atualmente, está sob a coordenação do Professor Dr. Marcelo Almeida

\footnotetext{
${ }^{5} \mathrm{http} / / /$ www.gepeticem.ufrrj.br/materiais-educacionais/materiais-curriculares-educativos
} 
Bairral.

Figura 2 - Ambiente virtual do Material Curricular Educativo do Gepeticem

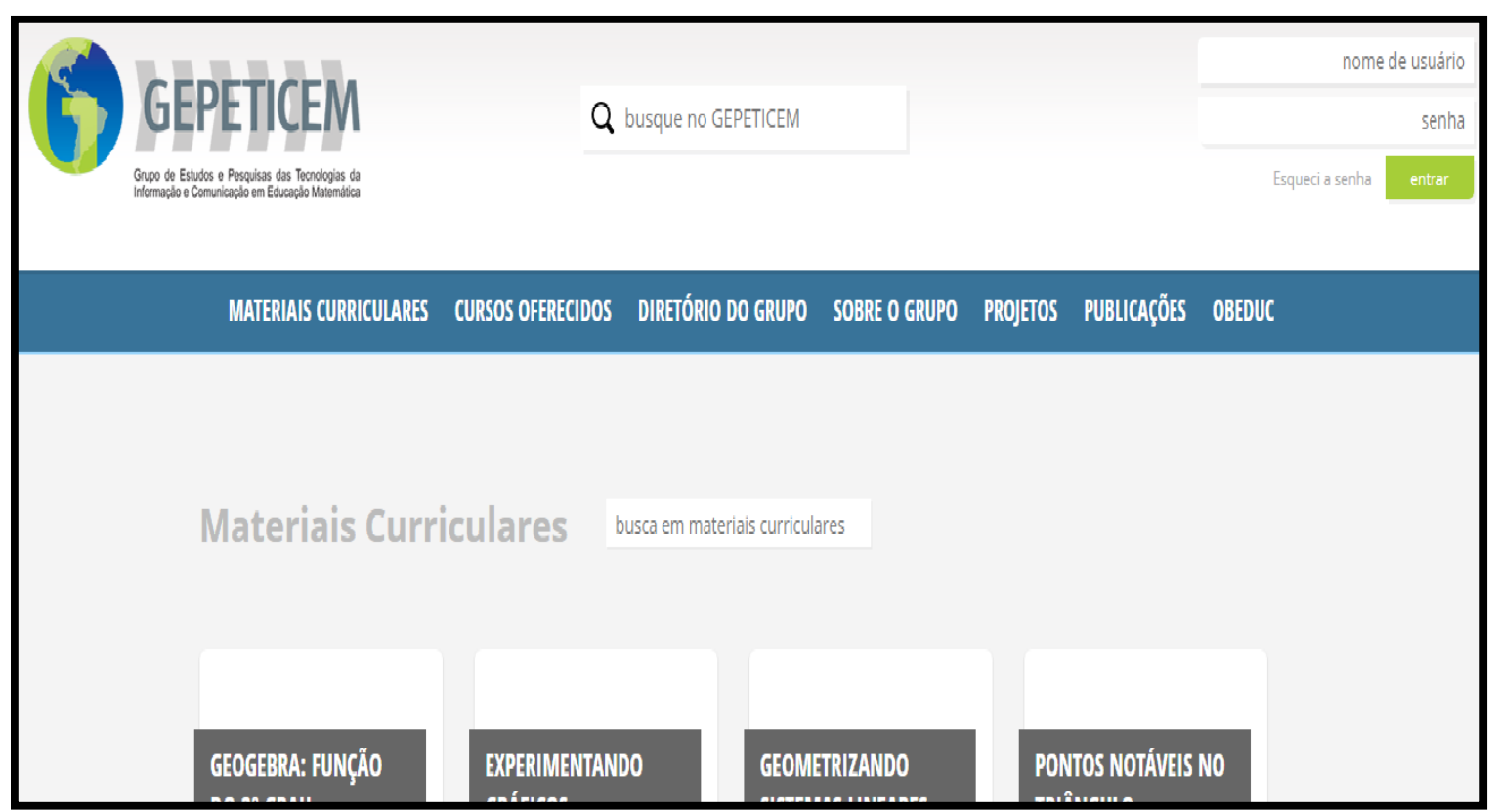

Fonte: www.gepeticem.ufrrj.br

Esse material explora conteúdos de Matemática do Ensino Fundamental II e Médio com uso do Ambiente de Geometria Dinâmica com Tecnologia de Informação e Comunicação. Cada MCE é composto pelos seguintes elementos: a) Apresentação; b) Tarefa; c) Respostas; d) Narrativa; e) Vídeos; f) Fórum; g) Chat; h) Comentários.

Material Curricular Educativo (MCE3) ${ }^{6}$ - produzido pelo grupo Observatório da Educação Matemática (OEM-Bahia) - grupo colaborativo formado por estudantes do curso de Licenciatura em Matemática; pesquisadores em Educação Matemática; professores que atuam no ensino da disciplina Matemática nos anos finais da Educação Fundamental e Ensino Médio. Atualmente, está credenciado como projeto de extensão junto à Universidade Federal da Bahia, tendo a coordenação da professora Dra. Andréia Maria Pereira de Oliveira e do Professor Dr. Jonei Cerqueira Barbosa.

${ }^{6}$ http://www.educacaomatematica.ufba.br

Periódico Horizontes - USF - Itatiba, SP - Brasil - e020033 
FIGURA 3 - Ambiente virtual do Material Curricular Educativo do OEM-Bahia

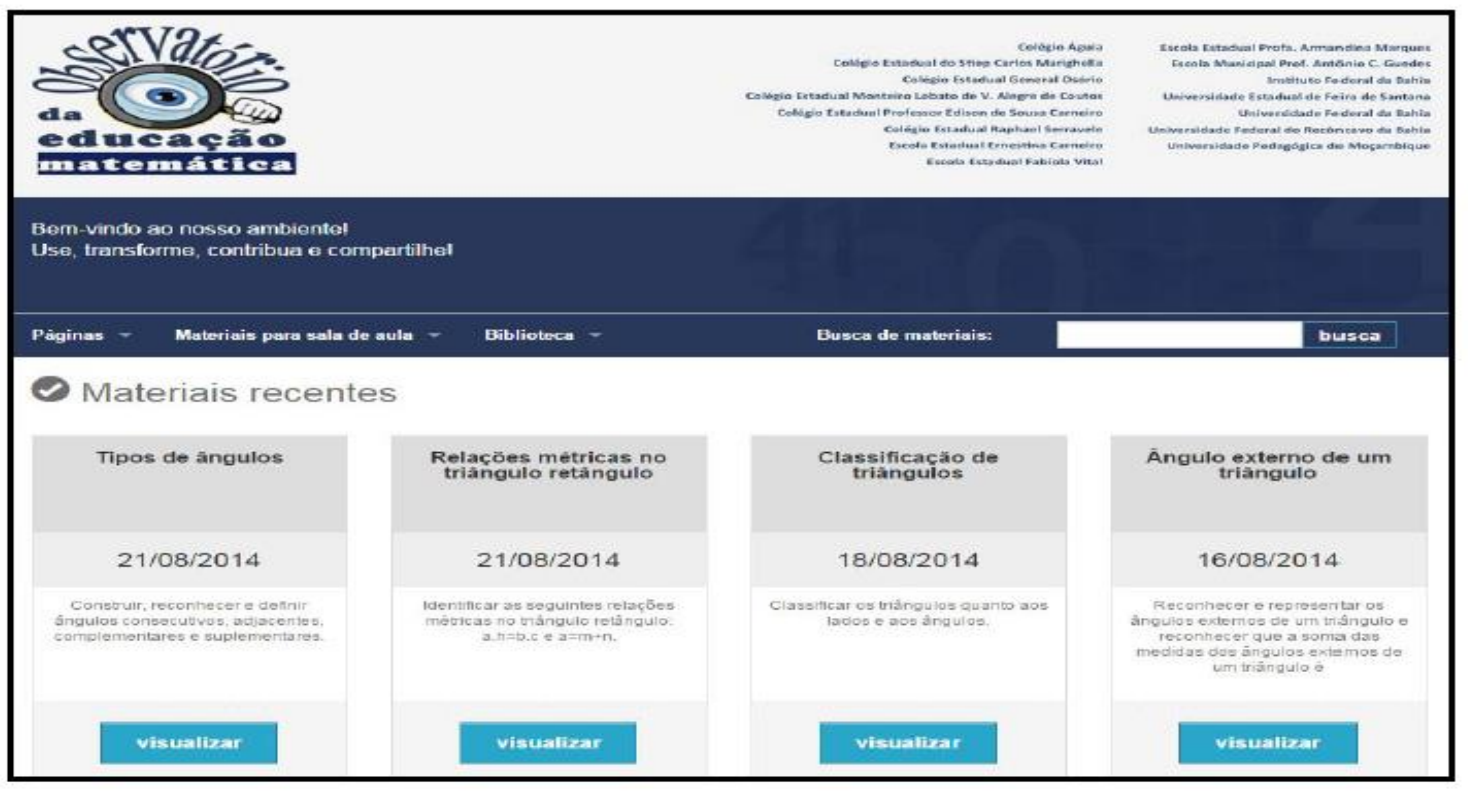

Fonte: www.educacaomatematica.ufba.br

Esse material explora conteúdos de Matemática do Ensino Fundamental II, sendo composto por: a) Material curricular; b) Material curricular comentado para o (a) professor(a); c) Solução do estudante; d) Narrativa; e) Solução do(a) professor; f) Planejamento; g) Vídeos.

A análise dos dados foi inspirada no modelo metodológico de investigação da Linguagem de Descrição desenvolvido por Bernstein (1990, 1996, 2000), o qual propõe linguagem de descrição interna e externa. A linguagem de descrição interna diz respeito aos constructos teóricos, enquanto que a linguagem de descrição externa corresponde aos textos dos Materiais Curriculares Educativos sobre Matemática.

\section{Apresentação e discussão dos dados}

Para compreender as relações entre discursos representados em textos de Materiais Curriculares Educativos sobre Matemática, apresentamos os resultados preliminares das nossas análises no que diz respeito às relações intradisciplinares e interdisciplinares e das relações entre 
os conteúdos acadêmicos e não acadêmicos.

As categorias analíticas foram estabelecidas a priori e sistematizadas a partir de um constante diálogo com os conceitos da teoria de Bernstein (2000). Neste artigo, apresentaremos duas dessas categorias nomeadas de Relações Intradisciplinares e Interdisciplinares e Relações entre os Conteúdos Acadêmicos e não Acadêmicos. O Quadro 1, a seguir, auxiliam na apresentação e discussão dessas duas categorias.

Quadro 1. Relações intradisciplinares e interdisciplinares presentes em textos dos MCE

\begin{tabular}{|c|c|c|c|c|}
\hline MCE & $\begin{array}{c}\text { Título da } \\
\text { tarefa } \\
\text { matemática } \\
\end{array}$ & Tarefa matemática & $\begin{array}{l}\text { Disciplinas } \\
\text { envolvidas }\end{array}$ & $\begin{array}{l}\text { Conteúdos } \\
\text { envolvidos }\end{array}$ \\
\hline MCE1 & Os colares & $\begin{array}{l}\text { Tarefa - Os colares } \\
\text { A Inês feztrềs colares, com contas pretase brancas, conforme as figuras 1,2e\}. } \\
\text { 1) Indique acima o número total de contas de cada } \\
\text { figura; 2) Continuando esta sequência de colares, } \\
\text { quantas contas teria, no total, o colar } \\
\text { correspondente à figura seguinte?; 3) E quantas } \\
\text { contas teria o colar correspondente à figura 8?; 4) } \\
\text { Descubra quantas contas teria, no total, o colar } \\
\text { correspondente à figura 19?; 5) Existe algum colar } \\
\text { na sequência que tenha 55 contas? Explique, } \\
\text { detalhadamente, o seu raciocínio; 6) Descreva uma } \\
\text { regra que Ihe permita determinar o número total } \\
\text { de contas de qualquer figura da sequência. }\end{array}$ & & Álgebra \\
\hline MCE2 & $\begin{array}{l}\text { Geometrizando } \\
\text { sistemas } \\
\text { lineares } 2 \times 2\end{array}$ & $\begin{array}{l}\text { Crie os controles deslizantes } \mathbf{a} \text {, } \mathbf{b} \text { e c com valor } \\
\text { mínimo }-5 \text {, valor máximo } 5 \text { e incremento mude } \\
\text { para } 1 . \text { O parâmetro a representa o coeficiente de } \\
\mathbf{x} \text { o parâmetro b representa o coeficiente de y e o } \\
\text { parâmetro c representa o termo independente. } \\
\text { Digite a equação no campo de entrada. Clique }\end{array}$ & & $\begin{array}{c}\text { Álgebra } \\
\text { Geometria } \\
\text { Sistemas } \\
\text { Lineares }\end{array}$ \\
\hline
\end{tabular}

Periódico Horizontes - USF - Itatiba, SP - Brasil - e020033 


\begin{tabular}{|c|c|c|c|}
\hline & & $\begin{array}{l}\text { enter e observe no campo gráfico a reta que } \\
\text { representa a equação. Clique na ferramenta mover } \\
\text { e escolha os parâmetros a, b e c do controle. Agora, } \\
\text { digite a equação e mova os parâmetros } \mathbf{a}, \mathbf{b} \text { e c. }\end{array}$ & \\
\hline MCE3 & $\begin{array}{c}\text { Descobrindo } \\
\text { relações } \\
\text { métricas no } \\
\text { triângulo } \\
\text { retângulo }\end{array}$ & $\begin{array}{l}\text { Caro(a) estudante, esta tarefa envolve relações } \\
\text { métricas que podemos estabelecer no triângulo } \\
\text { retângulo. Inicialmente, iremos nos organizar em } \\
\text { grupos e cada grupo receberá um kit com figuras } \\
\text { geométricas. Vamos começar?! a) Observe os } \\
\text { triângulos que você recebeu e responda às } \\
\text { seguintes questões: b) O que há em comum entre } \\
\text { eles? Nos dois triângulos sem identificação nos } \\
\text { lados, considere a hipotenusa como a base e trace } \\
\text { a altura do triângulo em relação à base. Em } \\
\text { seguida, corte os dois triângulos no segmento de } \\
\text { reta que você traçou. O que você obteve? Nomeie } \\
\text { os lados das figuras que você obteve quando } \\
\text { cortou os triângulos. Observe e compare os dois } \\
\text { triângulos que têm identificação e registre suas } \\
\text { observações. }\end{array}$ & $\begin{array}{c}\text { Geometria } \\
\text { Trigonometria }\end{array}$ \\
\hline
\end{tabular}

Fonte: Dados da pesquisa.

\section{Relações entre discursos intradisciplinares e interdisciplinares}

Vamos, agora, analisar as relações entre discursos. Para isso, inicialmente, analisamos as relações intradisciplinares. Compreendemos as relações intradisciplinares como as relações entre conteúdos matemáticos que o(a) professor(a) consegue estabelecer ao desenvolver uma tarefa matemática, enquanto as relações interdisciplinares são relações entre diferentes disciplinas, por exemplo, a relação entre determinados conteúdos de Matemática com a Biologia ou Geografia (PRADO; OLIVEIRA; BARBOSA, 2016; BERNSTEIN, 2000).

Os dados apresentados no Quadro 1 referem-se às tarefas matemáticas representadas nos Materiais Curriculares Educativos sobre Matemática analisados, por exemplo, os textos dos MCE2 e MCE3 abarcaram tarefas matemáticas com foco em Geometria. O texto do MCE1 focou na Álgebra. De um modo geral, os textos dos três MCE envolveram possíveis conteúdos matemáticos em suas tarefas matemáticas, em particular, conteúdos de Álgebra, Geometria, Trigonometria. Uma vez que toda disciplina (no nosso caso, Matemática) precisa de uma lógica de organização para que o(a) professor(a) possa gradativamente ir construindo com estudantes um conhecimento articulado, sempre que possível retornar ao conteúdo para juntar aos novos 
dos quais apresentam relações (RODRIGUES, 2015).

Isso denota que, para resolver a tarefa matemática do Material Curricular Educativo sobre Matemática, o(a) estudante passaria a utilizar mais de um conteúdo matemático, por exemplo, no texto do MCE3, no mínimo, poderia apresentar os conteúdos de Geometria e Trigonometria na estratégia de resolução, de modo que estudantes percebessem as possíveis combinações entre os diferentes conteúdos. Assim, a presença das relações intradisciplinares nos textos dos MCE se justifica porque o estabelecimento de relações entre os conteúdos de uma mesma disciplina pode favorecer a constituição de uma visão integradora da disciplina escolar (GALIAN, 2011).

Com base nos dados advindos dessa análise, podemos inferir que a prática pedagógica reportada nos três textos dos MCE se caracteriza por uma tarefa matemática em que o(a) professor recorre a outros conteúdos distintos para abordar o conteúdo que está desenvolvendo em sala de aula. Ao nosso ver, isso pode caracterizar que existem relações entre os conteúdos matemáticos em uma mesma tarefa matemática, isto é, apresentaram uma aproximação entre conteúdos, caracterizando uma classificação enfraquecida para as relações intradisciplinares.

Morais, Neves e Ferreira (2019) e trabalhos realizados pelo grupo Estudos Sociológicos de Sala em Aula (ESSA) argumentam que o(a) professor(a), ao promover uma classificação enfraquecida no desenvolvimento do conteúdo na sala de aula, especificamente, no que diz respeito à explicação de conteúdos novos e retomadas de outros trabalhados em séries anteriores, pode ocorrer um aproveitamento no processo de ensino e de aprendizagem da disciplina Matemática, pois estudantes relacionam e compreendem os novos conteúdos/conceitos, possibilitando discutir melhor as explicações quando estão desenvolvendo seus textos ao resolver a tarefa matemática.

Prado (2014), em uma análise documental, numa abordagem qualitativa, analisou as relações entre discursos expressas nos textos dos Materiais Curriculares Educativos sobre modelagem matemática. De acordo com a autora, os resultados apontaram que os conteúdos encontram-se integrados por meio da tarefa matemática nos textos desses materiais. Isso significa que, na prática pedagógica sugerida nos textos dos $\mathrm{MCE}$, os conteúdos são integrados por meio da tarefa, caracterizando uma classificação enfraquecida.

Em relação às relações interdisciplinares, as três tarefas matemáticas representadas no 
Quadro 1 não expressam relações entre diferentes disciplinas escolares que possam realizar articulação entre a Matemática e outra disciplina escolar, ambos os textos se concentraram na disciplina Matemática. A prática pedagógica reportada nos três textos dos MCE se caracteriza por uma tarefa matemática em que o(a) professor não se refere ao conteúdo de outras disciplinas. No entanto, acreditamos que é necessário fazer com que as disciplinas se encontrem e dialoguem em torno de necessidades significativas e concretas, eleitas como importantes para a formação de estudantes (LAPA; BEJARANO; PENIDO, 2011). Em nossa análise, podemos inferir que a relação interdisciplinar da prática pedagógica apresenta um nítido distanciamento entre as disciplinas escolares, caracterizando, assim, uma classificação fortalecida na relação interdisciplinar.

Silva (2017) apresentou um estudo qualitativo, cujo objetivo foi identificar e analisar as relações de poder na negociação de significados em uma Comunidade de Prática formada por acadêmicos da universidade e professores(as) da Educação Básica, os quais se reúnem para produzirem Materiais Curriculares Educativos de Matemática. Sendo assim, segunda a autora, os resultados apresentaram uma classificação forte para a relação entre os discursos interdisciplinares, pois os membros se envolveram em ações como falar, conversar, pensar, perceber, interpretar, concordar, discordar e trocar informações ou ideias e decidiram concentrar a tarefa do MCE na Matemática, pois não houve uma aproximação entre diferentes disciplinas escolares.

Silva (2012) analisou as tarefas sobre o tema meio ambiente em textos de livros didáticos. Como resultado, a autora indicou uma classificação fortalecida na relação interdisciplinar, significando a existência de uma fronteira bem nítida entre os conteúdos, ou seja, os conteúdos representados nas tarefas devem estar separados e a Biologia, que é a área central, deve permear todo o processo de apropriação do conhecimento.

Assim como nos estudos de Morais, Neves e Ferreira (2019), Silva (2017), Prado (2014) e Silva (2012), em que argumentaram a necessidade de os textos dos Materiais Curriculares Educativos focarem com mais pontualidade nas relações interdisciplinares, no nosso estudo, a análise desses conteúdos, aliados às teorias que sustentam este artigo, nos levou a inferir que os estudantes compreendem e aprendem as tarefas matemáticas presentes nos textos dos MCE. É necessário que professores que ensinam Matemática promovam nas práticas pedagógicas 
relações intradisciplinares e interdisciplinares no processo de ensino e de aprendizagem, pois estas relações são importantes em uma prática pedagógica de exigência conceitual (SOUZA; SILVA; SANTOS, 2017).

\section{Relações entre discursos acadêmicos e não acadêmicos}

As relações entre conteúdos acadêmicos/não acadêmicos são relações em que o(a) professor(a) toma "como ponto de partida o que o aluno sabe acerca dos fenômenos estudados e, a partir daí, avança para conhecimentos e competências mais complexos" (GALIAN, 2011, p.771), ou também os conteúdos acadêmicos como aqueles relativos às ciências e outros campos que permeiam as instituições acadêmicas. Já os conteúdos não acadêmicos caracterizam-se por conteúdos relacionados às situações do cotidiano (PRADO; OLIVEIRA; BARBOSA, 2016; BERNSTEIN, 2000).

Como podemos perceber no Quadro 1, em particular, na terceira coluna, as três tarefas matemáticas representadas nos textos dos Materiais Curriculares Educativos sobre Matemática lidavam apenas com conteúdos da disciplina Matemática ao requerer dos estudantes análise e busca de padrões comuns na apresentação de sentenças matemáticas. Nesse caso, os conteúdos acadêmicos estão relacionados à Matemática, a qual possui uma linguagem especializada e formal que inclui regras e símbolos próprios. Não observamos nos textos menções aos conteúdos não acadêmicos, cujas ideias do senso comum ou da vida cotidiana de estudantes ou situação não demandam uma formalização, mas são muito utilizadas na sociedade (PRADO; OLIVEIRA; BARBOSA, 2014; BERNSTEIN, 2000).

De modo geral, podemos deduzir que as três tarefas matemáticas representadas nos textos dos Materiais Curriculares Educativos sobre Matemática (Quadro 1, Coluna 3) apresentam uma linguagem matemática formal, específica da disciplina Matemática, a partir da identificação de padrões e regularidades. Nelas, na prática pedagógica reportada nos textos dos materiais, o(a) professor(a) não utilizou conhecimentos do dia a dia, isto é, conteúdos do senso comum para auxiliar a compreensão de estudantes. Entretanto, havia um predomínio de conteúdos acadêmicos, demarcando-os e distanciando-os dos conteúdos não acadêmicos. Isso resultou numa classificação forte (PRADO; OLIVEIRA; BARBOSA, 2014; BERNSTEIN, 2000). 
Estudos empíricos sobre Materiais Curriculares Educativos sobre Matemática têm mostrado as relações entre os conteúdos acadêmicos e não acadêmicos (SILVA, 2017; SILVA, 2012).

Prado, Oliveira e Barbosa (2017) analisaram as relações entre discursos acadêmicos e não acadêmicos expressas nos textos dos MCE sobre modelagem matemática. Os resultados mostraram que há explícitas indicações sobre o fazer referência ao discurso não acadêmico e um apelo à relação entre os dois tipos de discursos caracterizados nas soluções de estudantes. As conclusões apontaram que as relações entre discursos acadêmicos e não acadêmicos foram caracterizadas por uma classificação enfraquecida, pois o discurso acadêmico é abordado a partir de exemplos do discurso não acadêmico, existindo uma expressa relação entre os dois tipos de discursos.

De maneira similar, Silva (2017) analisou os discursos acadêmicos e os não acadêmicos em textos de tarefas matemática produzidas por acadêmicos da universidade e professores da Educação Básica, os quais se reúnem para produzirem Materiais Curriculares Educativos sobre Matemática. Os resultados apontaram que a tarefa matemática tratava da articulação entre a linguagem formal da Matemática e a linguagem cotidiana, por meio da noção intuitiva de lucro e prejuízo, inferindo que havia uma aproximação entre as fronteiras dos discursos acadêmicos e não acadêmicos, resultando numa classificação fraca.

Silva (2012) examinou as relações entre discursos acadêmicos e não acadêmicos nos textos das tarefas relacionadas ao ambiente nos livros didáticos. Os resultados mostram que os textos das tarefas relacionadas ao ambiente nos livros didáticos apresentam descontinuidade entre os discursos acadêmicos e não acadêmicos, isto é, não apresentam indicações aos conteúdos relacionados à realidade do(a) estudante, o que produz uma classificação fortalecida, caracterizando uma tensão no que se refere à abordagem do tema "Ambiente" nas Ciências Biológicas e outros tipos de discursos relacionados ao mesmo tema.

As investigações supracitadas apresentam algumas características comuns ao nosso artigo, como o aporte teórico (Basil Bernstein), o objeto de estudo (relação material/professor/estudante) e o tipo de linguagem (as interações discursivas). Além disso, trazem como diferencial, para que, de fato, a pesquisa se justifique, as relações intradisciplinares e interdisciplinares veiculadas em textos de Materiais Curriculares Educativos sobre Matemática que ainda não haviam passado pela 
análise documental sob a ótica teórico-metodológico de Basil Bernstein.

De modo geral, os estudos de Prado, Oliveira e Barbosa (2017), Silva (2017) e Silva (2012) mostram exemplos de investigações que reforçam a necessidade da combinação dos discursos acadêmicos e não acadêmicos presentes em textos de MCE. Em nosso artigo, torna-se evidente o papel da prática pedagógica desempenhada no desenvolvimento da tarefa matemática e, por conseguinte, extrair o sentido da mensagem que compõe a relação intradisciplinar e interdisciplinar e conteúdos acadêmicos e não acadêmicos, no qual foi possível retirar as seguintes características da mensagem da prática pedagógica representada em texto de Materiais Curriculares Educativos sobre Matemática.

Na explicação/discussão da tarefa matemática em sala de aula, o(a) professor(a) aborda conteúdos matemáticos na prática pedagógica (relação intradisciplinar), resultando numa classificação fraca; na explicação/discussão da tarefa matemática em sala de aula, o(a) professor(a) não se refere ao conteúdo de outras disciplinas escolares e às possíveis relações destes com conteúdos matemáticos na prática pedagógica (relação interdisciplinar), resultando numa classificação forte; por fim, não há referências à articulação entre os conteúdos acadêmicos e não acadêmicos e/ou referências a espaços de aprendizagem fora dos espaços escolares (classificação forte).

\section{Considerações finais}

De acordo com o objetivo proposto para este estudo - identificar e compreender as relações entre discursos representados em textos de Materiais Curriculares Educativos sobre Matemática - acreditamos que, a partir dos dados apresentados e analisados, foi possível alcançar tal objetivo. Para responder à questão problematizadora - Como as relações entre os discursos (intradisciplinares, interdisciplinares, acadêmicos e os não acadêmicos) são representadas nos textos dos MCE? -, dividimos nosso artigo em duas categorias.

Na terceira categoria - Relações entre discursos intradisciplinares e interdisciplinares -, identificamos que há um silenciamento do discurso interdisciplinar representado nos textos dos Materiais Curriculares Educativos sobre Matemática. Com isso, a tarefa matemática apresenta um grau de classificação forte, pois não se estabelecem quaisquer relações dos conteúdos da 
disciplina com conteúdos de outras disciplinas do currículo. Com isso, percebemos que a prática pedagógica, que é reportada nos textos dos materiais, mostra uma relação explícita no discurso intradisciplinar ao desenvolver o conteúdo matemático na sala de aula.

$\mathrm{Na}$ terceira categoria - Relações entre discursos acadêmicos e não acadêmicos -, identificamos que há um distanciamento do discurso acadêmico do não acadêmico, que foi negado nos textos dos MCE. Nas tarefas matemáticas analisadas, apresentam uma classificação forte, evidenciando não haver relação entre os dois tipos de discursos, isso significa que não se valorizou o discurso do cotidiano para a aprendizagem do discurso acadêmico no desenvolvimento do conteúdo na sala de aula. Com isso, vimos que a prática pedagógica que é veiculada nos textos dos materiais evidencia o reconhecimento do discurso acadêmico.

Portanto, a identificação e a caracterização dessas duas categorias contribuem para que as pesquisas sobre a formação de professores que ensinam Matemática evidenciem cada vez mais a necessidade de se articular as relações entre os discursos (intradisciplinares, interdisciplinares, acadêmicos e os não acadêmicos) na prática pedagógica. Diante disso, este artigo pode trazer implicações para a formação (inicial e/ou continuada) de professores que ensinam Matemática, contribuindo para a discussão na área de Educação Matemática e Educação, no que tange ao uso dos textos dos Materiais Curriculares Educativos sobre Matemática tanto em cursos de formação quanto nos que estão em pleno exercício de suas atividades na Educação Básica.

\section{Referências}

BARBOSA, J. C.; OLIVEIRA, A. M. P. Materiais curriculares e professores que ensinam matemática. Estudos Avançados, n.32, v.94, 2018.

BERNSTEIN, B. Class, codes and control, vol. IV: the structuring of pedagogic discourse. London: Routledge, 1990.

BERNSTEIN, B. A estruturação do discurso pedagógico: classe, códico e controle. Petrópolis: Vozes, 1996.

BERNSTEIN, B. Pedagogy, symbolic control and identify: theory, research, critique. Lanham: Rowman \& Littlefield Publishers, 2000. 
COIMBRA, J. A. A. Considerações sobre a interdisciplinaridade. In: PHILLIPI JUNIOR, A.; TUCCI, C. E. M.; HOGAN, D. J.; NAVEGANTES, R. (orgs). Interdisciplinaridade em ciências ambientais. São Paulo: Signus, 2000, p.52-70.

DAVIS, E. A.; PALINCSAR, A. S.; SMIRTH, P. S.; ARIAS, A. M.; KADEMIAN, S. M. Educative curriculum materials: uptake, impact, and implications for research and design. Educational Researcher, v.46, n.6, p.293-304, 2017.

DUKE, N. K.; BECK, S. W. Education should consider alternative forms for the dissertation. Educational Researcher, Washington, v.28, n.3, p.31-36, 1999.

FLICK, U. Introdução à pesquisa qualitativa. Porto Alegre: Artmed, 2009.

GALIAN, C. V. A. A recontextualização e o nível de exigência conceitual do conhecimento escolar. Educação \& Pesquisa, vol. 37, n.4, p.763-777, 2011. Disponível em: http://www.revistas.usp.br/ep/article/view/28300/30151. Acesso em: 25 junho 2019.

GIL, A. C. Como elaborar projetos de pesquisa. 5.ed. São Paulo: atlas, 2010.

LAPA, J. M.; BEJARANO, N. R.; PENIDO, M. C. M. Interdisciplinaridade e o ensino de ciências: uma análise da produção recente. In: ENCONTRO NACIONAL DE PESQUISA EM EDUCAÇÃO EM CIÊNCIAS, 8, 2011. Campinas. Anais eletrônicos [...]. Campinas: ABRAPEC, 2011. Disponível em: http://www.nutes.ufrj.br/abrapec/viienpec/resumos/R0065-1.pdf. Acesso em 25/06/19.

MORAIS, A. M.; NEVES, I. P.; FERREIRA, S. O currículo nas suas dimensões estrutural e interacional: perspectiva de Basil Bernstein. Práxis Educativa, v.14, n.2, p.405-431, 2019.

OLIVEIRA, A. M. P. Modelagem matemática e as tensões nos discursos dos professores. 2010. 200f. Tese (Doutorado em Ensino, Filosofia e História das Ciências) - Programa de PósGraduação em Ensino, Filosofia e História das Ciências, Universidade Federal da Bahia, Salvador, 2010.

PRADO, A. S. As imagens da prática pedagógica nos textos dos materiais curriculares educativos sobre modelagem matemática. 2014. 111f. Dissertação (Mestrado em Ensino, Filosofia e História das Ciências) - Universidade Federal da Bahia, Salvador, 2014.

PRADO, A. S.; OLIVEIRA, A. M.; BARBOSA, J. C. Uma análise sobre a imagem da dimensão interacional da prática pedagógica em materiais curriculares educativos. Educação Matemática Pesquisa, São Paulo (SP), v.16, n.02, p.505-535, 2014.

PRADO, A. S.; OLIVEIRA, A. M.; BARBOSA, J. C. Uma análise sobre a imagem da dimensão estrutural da prática pedagógica em materiais curriculares educativos. Bolema-Boletim de Educação Matemática, Rio Claro (SP), v.30, n.55, p.738-762, 2016.

REMILLARD, J.; KIM, K. Knowledge of curriculum embedded mathematics: exploring a critical 
domain of teaching. Educational Studies in Mathematics, 2017. p.1-17.

RICHARDSON, R. J. et al. Pesquisa social: métodos e técnicas. 3. ed. São Paulo: Atlas, 1999.

ROCKWELL, E. La experiencia etnográfica. Buenos Aires: Paidós, 2009.

RODRIGUES, A. C. C. Relações intradisciplinares e interdisciplinares no ensino da didática no curso de pedagogia. In: REUNIÃO NACIONAL DA ANPED, 37, 2015, Florianópolis. Anais eletrônicos [...]. Florianópolis: ANPED, 2015. Disponível em:

http://www.anped.org.br/sites/default/files/trabalho-gt04-3686.pdf. Acesso em: 10 jun. 2018.

SCHNEIDER, R. M.; KRAJCIK, J. Supporting science teacher learning: the role of educative curriculum materials. Journal of Science Teacher Education, New York, v.13, n.3, p.221-45, 2002.

SILVA, L. A. Licenciados em computação e saberes pedagógicos: cobranças de uma pedagogia da ação. 2014. 167f. Tese (Doutorado em Ensino, Filosofia e História das Ciências) - Programa de Pós-Graduação em Ensino, Filosofia e História das Ciências, Universidade Federal da Bahia, Salvador, 2017.

SILVA, S. N. O tema ambiente em um livro didático de Biologia do ensino médio: uma análise à luz da teoria sociológica de Basil Bernstein.2012. 206f. Tese (Doutorado em Ensino, Filosofia e História das Ciências) - Programa de Pós-Graduação em Ensino, Filosofia e História das Ciências, Universidade Federal da Bahia, Salvador, 2012.

SOUZA, R. V.; SILVA, R. L.; SANTOS, B. F. Intradisciplinaridade e interdisciplinaridade na prática pedagógica de um professor licenciado em Química que também leciona Física. In: ENCONTRO NACIONAL DE PESQUISA EM EDUCAÇÃO EM CIÊNCIAS - ENPEC, 11., 2017, Florianópolis. Anais [...]. Universidade Federal de Santa Catarina, Florianópolis, SC, 2017.

Recebido em janeiro 2020.

Aprovado em maio 2020. 